\title{
CORRELAÇÕES ENTRE QUALIDADE DE VIDA NO TRABALHO E COMPROMETIMENTO ORGANIZACIONAL: ESTUDO EM UMA UNIDADE DE VAREJO DE VESTUÁRIO NA CIDADE DE JOINVILLE/SC
}

\section{CORRELATIONS BETWEEN QUALITY OF WORK LIFE AND ORGANIZATIONAL COMMITMENT - CLOTHING RETAIL STORE IN JOINVILLE/SC/BRAZIL}

Eduardo Zanardi (UTFPR) eduardo.zanardi@outlook.com

Luiz Alberto Pilatti (UTFPR) lapilatti@utfpr.edu.br

Celso Bilynkievycz dos Santos (UTFPR) bilynkievycz@uepg.br

Heloisa Godoi (UFSC) heloisagodoi@gmail.com

Patricia Del Castanhel Claumann (UFSC) patricia.dcc@hotmail.com

\section{ERRATA}

Na página 582, no primeiro parágrafo, onde está escrito: "Respeitando essas diretrizes, os autores elaboraram um instrumento baseado em questionário e que foi dividido em duas partes, ambas as partes possuem reposta na escala tipo likert com 7 posições."

Leia-se: "Respeitando essas diretrizes, os autores elaboraram um instrumento na forma de questionário que foi dividido em duas partes, ambas possuem respostas na escala tipo likert com 7 posições. Este instrumento foi adaptado, traduzido e validado por Pedroso et al. (2010) apresentando a seguinte configuração:" 
Nessa mesma página (582), o texto deve ser apresentado em formato de quadro, incluindo a fonte, conforme a seguir:

Quadro 3.1 - Instrumento Hackman e Oldham, 1974

\section{Primeira parte - Uma pergunta relacionada a cada dimensão}

1. Qual é o nível de autonomia existente no seu trabalho? Até que ponto lhe é permitido decidir a maneira de realizar suas tarefas?

2. O quanto você desenvolve em seu trabalho atividades do inicio ao fim? As atividades possuem inicio e fim óbvio? Ou é apenas uma etapa de uma atividade, finalizada por outras pessoas ou máquinas?

3. Qual o nível de variedade presente no seu trabalho? Até que ponto o trabalho the exige realizar tarefas diferentes, que requerem habilidades distintas?

4. De um modo geral, o quão significante ou importante é o seu trabalho? O resultado do seu trabalho influencia na vida ou no bem-estar de outras pessoas?

5. O quanto você recebe informações sobre o seu desempenho no trabalho? Você tem conhecimento se o seu trabalho tem sido bem executado-através de algum "feedback" que colegas de trabalho ou supervisores fornecem?

Segunda parte - Afirmações relacionadas às cinco dimensões

6. Meu trabalho exige que eu utilize diversas habilidades complexas ou de alto-nível.

7. Meu trabalho é organizado de forma a não me possibilitar a realização de atividades completas, do inicio ao fim.

8. O simples fato de realizar o trabalho me proporciona muitas chances para compreender 0 quão bem eu venho o fazendo.

9. O trabalho é bastante extenso e repetitivo.

10. A qualidade com a qual realizo o meu trabalho pode afetar muitas pessoas.

11. Em meu trabalho não tenho nenhuma oportunidade de tomar iniciativas ou decisões.

12. Em meu trabalho tenho a oportunidade de terminar as atividades que iniciei.

13. Meu trabalho fornece poucas informações sobre o desempenho com o qual eu o realizo.

14. Em meu trabalho possuo independência e liberdade para realizá-lo da forma que eu preferir.

15. Meu trabalho em si não é muito importante ou significante para a empresa de forma global. Fonte: adaptado de Pedroso (2010)

Na página 584 onde está escrito: "Posteriormente, Rushel (1993) adaptou 0 modelo existe e atribuiu indicadores para quantificar cada uma das problemáticas".

Leia-se: "Posteriormente, Ruschel (1993, apud FERNANDES, 1996) adaptou o modelo existente e atribuiu indicadores para quantificar cada uma das problemáticas".

Sendo assim, incluem-se as seguintes referências no estudo: 
ALLEN, N. J.; MEYER, J. P. The measurement and antecedents of affective, continuance and normative commitment to the organization. Journal of Occupational Psychology, v. 63, p. 01-18, 1990.

FERNANDES, E. Qualidade de vida no trabalho: como medir para melhorar. 2. ed. Salvador: Casa da Qualidade, 1996.

HACKMAN, J. R.; OLDHAM, G. R. The job diagnostic survey: an instrument for the diagnosis of jobs and the evaluation of job redesign projects. Technical report n. 4, Department of Administrative Sciences of Yale University, may 1974.

PEDROSO, B.; PILATTI, L.A.; SANTOS, C.B.; SANTOS JUNIOR, G. Potencial motivador do trabalho: tradução e adaptação cultural do instrumento de Hackman e Oldham. Revista Produção Online 10 (3), p. 670-697, 2010.

PEDROSO, B. Desenvolvimento do TQWL-42: Um instrumento de avaliação da qualidade de vida no trabalho. 2010. Dissertação de mestrado em engenharia de produção. PPGEP. Universidade Tecnológica Federal do Paraná.

Fonte: adaptado de Pedroso (2010) 